invited review or symposium paper. As a result, the first impact of each paper may have been slower, but availability of a more detailed initial exposition than could have appeared in a 'top' journal probably helped the ideas to be understood more readily.

Bob Michell

School of Biosciences, University of Birmingham, Edgbaston, Birmingham B15 2TT, UK

1. Lawrence, P. A. Nature 422, 259-261 (2003).

2. Streb, H., Irvine, R. F., Berridge, M. J. \& Schulz, I. Nature 306, $67-69(1983)$

3. Hokin, M. R. \& Hokin, L. E. J. Biol. Chem. 203, 967-977 (1953)

4. Michell, R. H. in Phosphoinositides and Receptor Mechanisms (ed. Putney, J. W.) 1-24 (Alan R. Liss, New York, 1986).

5. Michell, R. H. \& Lapetina, E. G. Nature New Biol. 240, 258-260 (1972).

6. Michell, R. H. Biochim. Biophys. Acta 415, 81-147 (1975).

7. Creba, J. A. et al. Biochem. J. 212, 733-747 (1983).

8. Michell, R. H. Phil. Trans. R. Soc. Lond. B 296, 123-138 (1981).

\section{The system rewards a} dishonest approach

Sir - I strongly support the views of Peter A. Lawrence in his Commentary about the politics of publication (Nature 422, 259-261) and congratulate Nature for publishing this piece.

As Lawrence says, the assessment of science is, regrettably, moving towards an "audit society", in which the fact of having published in high-impact journals is seen as more important than the content of the papers themselves.

There are two further problems that arise from this assessment of individuals through the locations of their publications. First, only a minority of submissions get sent out for review in high-profile journals. As a regular reviewer for Nature, I find that submissions often contain some 'bold claim' about the extraordinary novelty of the results presented. These bold claims are designed to get the paper into the review process. In my experience, reviewers often find that the work in the manuscript is good science and quite interesting, but that the bold claim typically cannot be justified by the data that have been presented. The authors then dilute or remove the bold claim, with the result that a good, quite interesting manuscript is published, but is no better than many simultaneously being published in specialized journals. The difference is that the Nature submission began with hyperbole and overselling, the traces of which have vanished from the final version. There is a danger that authors are rewarded for a fundamentally dishonest approach.

Second, the review process has no power to screen for false authorship. Often, a large laboratory is likely to get one or more papers in high-impact journals, and it is very easy for the group leader to insert the name of a favoured postdoc who 'needs' a publication for some career goal into the list of authors, notwithstanding the minor contribution that the individual made to the work. The young scientist's CV is enhanced, and the rewards follow, not just for the young scientist, but also sometimes for the group leader.

\section{John Brookfield}

Institute of Genetics, University of Nottingham, Queens Medical Centre, Nottingham NG7 2UH, UK

Nature's authorship policy is that authors are strongly encouraged to include a statement in the Acknowledgements to specify the actual contribution of each co-author. See www.nature.com/nature/submit/ policies/index.html\#2 — Editor, Correspondence

\section{Impact factors aren't top journals' sole attraction}

Sir - Peter A. Lawrence (Nature 422, $259-261 ; 2003)$ points out in his Commentary that a substantial amount of politics has become commonplace in the scientific-publication enterprise.

In the numerous fields that are a bit less brutal than the highly competitive biomedical sciences, there may be another compelling motivation for authors to seek publication in the highest-ranked journals. The top journals are the most likely to consult top referees successfully, thus providing authors with the most meaningful feedback. The problem of fierce competition and conflicts of interest, although undeniably present, is probably less severe in fields such as the geosciences, and the benefit of receiving timely, topnotch reviews - rather than off-the-point comments from perhaps less qualified referees — should not be underestimated. Torbjörn E. Törnqvist

Department of Earth and Environmental Sciences, University of Illinois at Chicago, 845 West Taylor Street, Chicago, Illinois 60607-7059, USA

\section{Disruption to science in developing countries}

Sir - I fully agree with the concern expressed by Peter A. Lawrence in his Commentary (Nature 422, 259-261; 2003) about how different strategies and manoeuvres adopted by scientists desperate to publish in a few top journals can be disruptive to the quality of research. But in addition, the policy of considering "the journal to be more important than the scientific message" is having an even more devastating effect on science in developing countries.

I am speaking not only of my experience in Brazil, but also of other countries of similar social and economic standing, where money - and money for science - is much scarcer than in developed countries. Why is it worse here than there?

First, of course, there is much less money to be invested in science, and thus its misuse is proportionally more detrimental. Second, the 'accountability culture' has been imported and widely adopted, with neither assessment of its validity nor critical analysis of its consequences. It is troublesome that such an essential issue has been taken for granted by the scientific community, which by definition is supposed to accept facts and procedures only when solid data leave no space for doubt.

Finally, a numerical assessment of scientific merit minimizes the number of important variables, and consequently reduces the possibilities of defining the priorities and scientific strategies that best fit local demands.

I am fully aware of the international character of science and of the universality of the criteria for judging its quality. However, this global view does not mean that each country should forsake its individuality and its capacity to define its own criteria and methods for assessing merit.

Marcello A. Barcinski

Department of Parasitology, University of São Paulo, Av. Lineu Prestes 1374,

São Paulo 05508-900, Brasil

\section{Separate achievements of the Humboldt brothers}

Sir - In contrast to the assertion made in your Editorial "Berlin's university crisis" (Nature 423, 101; 2003), the famous principle of the "unity of teaching and research" that forms the conceptual basis of modern academic education was not developed by the natural scientist Alexander von Humboldt (1769-1859); neither was he the "founder of the modern German higher-education system".

These achievements were those of his brother, the politician and linguist Wilhelm von Humboldt (1767-1835), who in 1810 founded the university of Berlin that carries his name today.

W. S. Peters

Institut für Allgemeine Botanik,

Justus-von-Liebig-Universität, Senckenbergstrasse 17-21, D-35390 Gießen, Germany 